\title{
STUDI ANALISIS DAYA DUKUNG PONDASI TIANG PADA PEMBANGUNAN GEDUNG LP3M UNIVERSITAS KADIRI
}

\author{
${ }^{1}$ Agata Iwan Candra, ${ }^{2}$ Anasrudin Yusuf, ${ }^{3}$ Amanda Rizky F. \\ ${ }^{1}$ Staf Pengajar Program Studi Teknik Sipil Fakultas Teknik Universitas Kadiri \\ ${ }^{2,3}$ Mahasiswa Program Studi Teknik Sipil Fakultas Teknik Universitas Kadiri \\ E-mail : ${ }^{1}$ iindiecom@gmail.com, 2 anasrudin@yahoo.com, ${ }^{3}$ ceugm14@gmail.com
}

\begin{abstract}
The foundation is a part of the building construction which is responsible for accepting and eradicating all the load from the building either live load or dead load from a land market building which is strong enough to support it. To determine the soil bearing capacity soil investigation needs to be done so that the building that are above the ground is not decreased (settlelment) is large enough, then the foundation must reach solid ground layer and the bearing capacity of the soil (bearing capacity) are permitted. Strous foundation and bored pile used if the ground conditions in the bottom of the building does not have sufficient load bearing capacity to carry the load or if the hard soil that has a strong carrying capacity is located very deep from the ground surface. The purpose of this study is to calculate the carrying capacity of Strous Meyerhoff and Begemann on sondir results.
\end{abstract}

Calculation results as follows:

Load Bearing Capacity of Single Pile Foundation

Diameter of pile $\quad=30 \mathrm{~cm}$

The depth of the pile $\quad=4.00$ meters

\begin{tabular}{|l|c|c|c|c|c|c|c|}
\hline \multirow{2}{*}{ Metode } & \multicolumn{7}{|c|}{ Diameter Tiang (cm) } \\
\cline { 2 - 9 } & $\varnothing 20$ & $\varnothing 25$ & $\varnothing 30$ & $\varnothing 35$ & $\varnothing 40$ & $\varnothing 45$ & $\varnothing 50$ \\
\hline Trofimankove & 21,43 & 27,97 & 34,97 & 42,45 & 50,40 & 58,82 & 67,71 \\
\hline Meyerhoff & 31,28 & 40,60 & 50,51 & 61,03 & 72,14 & 83,86 & 96,17 \\
\hline Begemann & 16,87 & 22,21 & 28,02 & 34,27 & 40,98 & 48,14 & 55,75 \\
\hline Cara Umum & 17,01 & 22,45 & 28,35 & 34,72 & 41,57 & 48,89 & 56,67 \\
\hline
\end{tabular}

\section{Power Capacity Support the Pile Group}

For $P_{\text {max }}=127$ Ton, taking into account the pile efficiency factor, thenumber and capacity of the pile group ultimit can be seen in table 4 as follows:

\begin{tabular}{|c|c|c|c|c|c|c|c|c|c|c|c|c|}
\hline \multirow{2}{*}{$\begin{array}{c}\text { Metode } \\
\text { Diameter } \\
\text { Tiang }\end{array}$} & \multicolumn{3}{|c|}{ Trofimankove } & \multicolumn{3}{|c|}{ Meyerhoff } & \multicolumn{3}{|c|}{ Begemann } & \multicolumn{3}{|c|}{ Cara Umum } \\
\hline & $\begin{array}{l}\text { P all } \\
\text { (Ton) }\end{array}$ & $\begin{array}{l}\text { Jmlh } \\
\text { Tiang }\end{array}$ & $\begin{array}{r}\text { P grup } \\
\text { (Ton) }\end{array}$ & $\begin{array}{l}\text { P all } \\
\text { (Ton) }\end{array}$ & $\begin{array}{l}\text { Jmlh } \\
\text { Tiang }\end{array}$ & $\begin{array}{r}\text { P grup } \\
\text { (Ton) }\end{array}$ & $\begin{array}{l}\text { P all } \\
\text { (Ton) }\end{array}$ & $\begin{array}{l}\text { Jmlh } \\
\text { Tiang }\end{array}$ & $\begin{array}{l}\text { P grup } \\
\text { (Ton) }\end{array}$ & $\begin{array}{l}\text { P all } \\
\text { (Ton) }\end{array}$ & $\begin{array}{l}\text { Jmlh } \\
\text { Tiang }\end{array}$ & $\begin{array}{r}\text { P grup } \\
\text { (Ton) }\end{array}$ \\
\hline$\varnothing 20$ & 21,43 & 9 & 130,58 & 31,28 & 6 & 134,64 & 16,87 & 9 & 102,77 & 17,01 & 9 & 103,67 \\
\hline$\varnothing 25$ & 27,97 & 7 & 132,53 & 40,60 & 5 & 145,62 & 22,21 & 9 & 135,36 & 22,45 & 9 & 136,77 \\
\hline$\varnothing 30$ & 34,97 & 6 & 150,53 & 50,51 & 4 & 153,11 & 28,02 & 7 & 132,77 & 28,35 & 7 & 134,35 \\
\hline$\varnothing 35$ & 42,45 & 4 & 128,67 & 61,03 & 3 & 138,74 & 34,27 & 6 & 147,51 & 34,72 & 6 & 149,46 \\
\hline$\varnothing 40$ & 50,40 & 4 & 152,76 & 72,14 & 3 & 164,00 & 40,98 & 5 & 146,98 & 41,57 & 5 & 149,11 \\
\hline$\varnothing 45$ & 58,82 & 3 & 133,71 & 83,86 & 2 & 147,40 & 48,14 & 4 & 145,90 & 48,89 & 4 & 148,18 \\
\hline$\varnothing 50$ & 67,71 & 3 & 153,93 & 96,17 & 2 & 169,04 & 55,75 & 4 & 168,97 & 56,67 & 3 & 128,84 \\
\hline
\end{tabular}

Keywords : soil bearing capacity, foundation, strouss, bored pile, sondir 


\section{PENDAHULUAN Tinjauan Umum}

Pondasi adalah suatu konstruksi pada bagian dasar bangunan (sub-structure) yang berfungsi meneruskan beban dari bagian atas struktur bangunan (upper-structure) ke lapisan tanah yang berada di bagian bawahnya tanpa mengakibatkan keruntuhan geser tanah, dan penurunan (settlement) tanah / pondasi yang berlebihan.

Pondasi harus di perhitungkan untuk dapat menjamin kestabilan bangunan terhadap berat sendiri, beban - beban bangunan, gaya gaya luar seperti tekanan angin, gempa, dan lain-lain. Disamping itu, tidak boleh terjadi penurunan melebihi batas yang diijinkan.

Bangunan gedung adalah wujud fisik hasil pekerjaan konstruksi yang menyatu dengan tempat kedudukannya, sebagian atau seluruhnya berada di atas dan/atau di dalam tanah dan/atau air, yang berfungsi sebagai tempat manusia melakukan kegiatannya, baik untuk hunian atau tempat tinggal, kegiatan keagamaan, kegiatan usaha, kegiatan sosial, budaya, maupun kegiatan khusus [1].

Saat ini makin banyak didirikan gedunggedung berukuran besar.Sehubungan dengan pembangunan ini, kerap kali dalam menentukan jenis kondisi bangunan timbul masalah-masalah yang diakibatkan oleh kondisi lapisan tanahnya.Hal ini terjadi pula pada pembangunan Gedung LP3M Universitas Kadiri. Pada waktu diadakan penyelidikan tanah (sondir), menunjukan lapisan tanah keras letaknya tidak terlalu dalam dari permukaan tanah.

Dengan diketahui kondisi lapisan tanah, dimana letak lapisan tanah keras berada tidak terlalu dalam dari permukaan tanah maka pemilihan jenis pondasi menggunakan system pondasi tiang (Strous Pile)

Pondasi merupakan bagian yang sangat penting, karena terletak pada bagian bawah dari struktur bangunan yang berfungsi memikul beban -beban, antara lain :beban hidup, beban bangunan sendiri,beban gempa dan lain - lain. Beban dari struktur bangunan tersebut didistribusikan melalui kolom dengan intensitas tegangan yang di ijinkan menurut nilai daya dukung tanah [2].

Dengan demikian, konstruksi pondasi pada suatu bangunan harus direncanakan sesuai dengan daya dukung tanah yang diijinkan sehingga konstruksi mampu berdiri dengan sempurna.

\section{Latar Belakang}

Sejalan dengan perkembangan pembangunan modern ini, makin banyak didirikan bangunan atau gedung-gedung tinggi. Dari pembangunannya sering timbul masalah-masalah yang diakibatkan oleh kondisi tanah. Hal ini disebabkan karena tanah tempat berdirinya bangunan adalah merupakan daerah yang labil tanahnya.

Dengan demikian, akhirnya timbul masalah dalam menentukan jenis pondasi yang layak dipergunakan pada pembangunan Gedung LP3M Universitas Kadiri.

Pondasi jenis tiang merupakan pondasi yang sering kali direncakan pada kondisi yang demikian. Dalam hal ini penulis mencoba membuat analisa perhitungan Pondasi StrousMetode Trofimankove, Metode Meyerhoff, Metode Begemann dan Cara Umum

\section{Rumusan Masalah}

Sesuai dengan latar belakang dan identifiksi masalah tersebut diatas, maka dapat diangkat rumusan masalahnya adalah :

1. Pada kedalaman berapa tanah di sekitar Gedung LP3M mampu menahan beban yang direncanakan?

2. Apakah mampu pondasi strousMetode Trofimankove, Metode Meyerhoff, Metode Begemann dan Cara Umumdigunakan dalam analisa perhitungan Gedung LP3M Universitas Kadiri?

\section{Batasan Masalah}

Untuk menghindari melebarnya permasalahan, untuk itu penulis membuat batasan-batasan permasalahan yang berhubungan dengan penulisan ini, Adapun batasan permasalahan pada perencanaan ini adalah :

1. Perhitungan daya dukung tiang berdasarkan kekuatan tanah.

2. Perhitungan daya dukung tiang kelompok.

3. Data pembebanan di asumsikan.

\section{Maksud Dan Tujuan}

Maksud yang akan dicapai dari penulisan studiperencanaan pondasi strous Metode Trofimankove, Metode Meyerhoff, Metode 
Begemanndan Cara Umum Gedung LP3M Universitas Kadiri adalah :

- Untuk menghitung daya dukung Strous Metode Trofimankove, Metode Meyerhoff, Metode Begemann dan Cara Umum tersebut terhadap hasil sondir.

Adapun tujuannya yaitu, untuk memenuhi penelitian dosen Univeritas Kadiri dan nantinya bisa dimanfaatkan sebagai acuan dalam perencaan lebih lanjut.

\section{METODOLOGI}

Bahan untuk menganalisis daya dukung pondasi menggunakan data pondasi tiang. Beberapa metode pengumpulan data antara lain :

- Metode observasi dengan mengambil data yang berhubungan dengan data teknis gedung dan pondasi diperoleh langsung dari proyek.

- Pengambilan data meliputi gambar lengkap (denah, potongan, detail-detail, denah pondasi, detail pondasi), data penyelidikan tanah yaitu data sondir.

- Membaca studi kepustakaan dengan membaca dan mengutip isi buku yang berhubungan dengan permasalahan yang ditinjau untuk melengkapi dan menyelesaikan tulisan artikel ini.

- Menghitung daya dukung pondasi berdasarkan data sondir dengan menggunakan metode Trofimankove (1974), metode Meyerhoff (1956), metode Begemann(1965), dan metode Cara Umum yang kemudian digunakan untuk menentukan jumlah tiang dengan mempertimbangkan daya dukung tiang kelompok, kemudian disimpulkan.

\section{HASIL DAN PEMBAHASAN}

\subsection{Beban Struktur Bangunan}

Hasil perhitungan

analisa

pembebanan dengan bantuan SAP2000, untuk beban maksimal bangunan yang bekerja pada pondasi $\left(\mathrm{P}_{\max }\right)=127$ ton

\subsection{Kapasitas Daya Dukung Pondasi Tiang}

\section{Tunggal}

Diameter tiang

Kedalaman tiang

$=30 \mathrm{~cm}$

$=4,00$ meter
1. Metode Trofimankove (1974)

Pall

$$
\begin{aligned}
& =\frac{0,75 \times 40 \times 706,86+(1054 / 1,5) \times 94,25}{2,5} \\
& =\frac{87430,52}{2,5} \\
& =34972,21 \mathrm{~kg}=34,97 \text { Ton }
\end{aligned}
$$

2. Metode Meyerhoff (1956)

$$
\begin{aligned}
\mathrm{qc}_{\mathrm{r}} & =\frac{(35+35+40+40+35+40+40+40)}{8} \\
& =38,125 \mathrm{~kg} / \mathrm{cm}^{2} \\
\mathrm{P} u l t & =38,125 \times 706,86+ \\
1054 \times & 94,25 \\
& =126286,13 \mathrm{~kg} \\
\text { Pall } & =\frac{126286,13}{2,5} \\
& =50514,45 \mathrm{~kg}=50,51 \text { Ton }
\end{aligned}
$$

3. Metode Begemann (1965)

$\mathrm{q}_{\mathrm{cu}}=$

$\underline{(40+30+25+25+30+35+35+35+40+40+35+40)}$

$=34,17 \mathrm{~kg} / \mathrm{cm}^{2}$

$\mathrm{q}_{\mathrm{cb}}=\frac{(40+40+40+30+30+30)}{6}=35$

$\mathrm{kg} / \mathrm{cm}^{2}$

qc $\quad=1 / 2 \times(34,17+35)=$

$34,58 \mathrm{~kg} / \mathrm{cm}^{2}$

$$
\begin{aligned}
\text { Pall } & =\frac{34,58 \times 706,86}{3}+\frac{1054 \times 94,25}{5} \\
& =8148,51+19867,43 \\
& =28015,94 \mathrm{~kg}=28,02 \text { Ton }
\end{aligned}
$$

4. Cara Umum

Pall =

$\frac{(0,75 \times 40 \times 706,86)+(0,5 \times 1054 \times 94,25)}{25}$

$$
\begin{aligned}
& =\frac{70874,33}{2,5} \\
& =28349,73 \mathrm{~kg}=28,35 \text { Ton }
\end{aligned}
$$

Dengan data-data yang sama, maka daya dukung ijin tiang tunggal untuk diameter jenis lain dapat dihitung dan dilihat dalam tabel 3 sebagai berikut :

Tabel 3. Daya Dukung Pondasi Tiang Tunggal, Pall (Ton)

\begin{tabular}{|l|c|c|c|c|c|c|c|}
\hline \multirow{2}{*}{ Metode } & \multicolumn{7}{|c|}{ Diameter Tiang (cm) } \\
\cline { 2 - 8 } & $\varnothing 20$ & $\varnothing 25$ & $\varnothing 30$ & $\varnothing 35$ & $\varnothing 40$ & $\varnothing 45$ & $\varnothing 50$ \\
\hline Trofimankove & 21,43 & 27,97 & 34,97 & 42,45 & 50,40 & 58,82 & 67,71 \\
\hline Meyerhoff & 31,28 & 40,60 & 50,51 & 61,03 & 72,14 & 83,86 & 96,17 \\
\hline Begemann & 16,87 & 22,21 & 28,02 & 34,27 & 40,98 & 48,14 & 55,75 \\
\hline Cara Umum & 17,01 & 22,45 & 28,35 & 34,72 & 41,57 & 48,89 & 56,67 \\
\hline
\end{tabular}




\subsection{Kapasitas Daya Dukung Kelompok Tiang}

Untuk $\mathrm{P}_{\max }=127$ Ton, dengan memperhatikan faktor efisiensi tiang, maka jumlah dan kapasitas ultimit kelompok tiang dapat dilihat dalam tabel 4 sebagai berikut :

Tabel 4. Daya Dukung Pondasi Kelompok Tiang, Pgrup (Ton)
5. Berdasarkan analisis kapasitas daya dukung kelompok tiang dengan menggunakan keempat metode tersebut, dapat diketahui bahwa metode Meyerhoff (1956) memberikan hasil yang paling ekonomis dibandingkan metode yang lain.

\begin{tabular}{|c|c|c|c|c|c|c|c|c|c|c|c|c|}
\hline \multirow{2}{*}{\begin{tabular}{|c|} 
Metode \\
Diameter \\
Tiang \\
\end{tabular}} & \multicolumn{3}{|c|}{ Trofimankove } & \multicolumn{3}{|c|}{ Meyerhoff } & \multicolumn{3}{|c|}{ Begemann } & \multicolumn{3}{|c|}{ Cara Umum } \\
\hline & $\begin{array}{l}\text { Pall } \\
\text { (Ton) }\end{array}$ & $\begin{array}{l}\text { Jmlh } \\
\text { Tiang }\end{array}$ & $\begin{array}{r}\text { P grup } \\
\text { (Ton) }\end{array}$ & $\begin{array}{l}\text { P all } \\
\text { (Ton) }\end{array}$ & $\begin{array}{l}\text { Jmlh } \\
\text { Tiang }\end{array}$ & $\begin{array}{r}\text { P grup } \\
\text { (Ton) }\end{array}$ & $\begin{array}{l}\text { Pall } \\
\text { (Ton) }\end{array}$ & $\begin{array}{l}\text { Jmlh } \\
\text { Tiang }\end{array}$ & $\begin{array}{r}\text { P grup } \\
\text { (Ton) }\end{array}$ & $\begin{array}{l}\mathrm{P} \text { all } \\
\text { (Ton) }\end{array}$ & $\begin{array}{l}\text { Jmlh } \\
\text { Tiang }\end{array}$ & $\begin{array}{r}\text { P grup } \\
\text { (Ton) }\end{array}$ \\
\hline$\varnothing 20$ & 21,43 & 9 & 130,58 & 31,28 & 6 & 134,64 & 16,87 & 9 & 102,77 & 17,01 & 9 & 103,67 \\
\hline$\varnothing 25$ & 27,97 & 7 & 132,53 & 40,60 & 5 & 145,62 & 22,21 & 9 & 135,36 & 22,45 & 9 & 136,77 \\
\hline$\varnothing 30$ & 34,97 & 6 & 150,53 & 50,51 & 4 & 153,11 & 28,02 & 7 & 132,77 & 28,35 & 7 & 134,35 \\
\hline$\varnothing 35$ & 42,45 & 4 & 128,67 & 61,03 & 3 & 138,74 & 34,27 & 6 & 147,51 & 34,72 & 6 & 149,46 \\
\hline$\varnothing 40$ & 50,40 & 4 & 152,76 & 72,14 & 3 & 164,00 & 40,98 & 5 & 146,98 & 41,57 & 5 & 149,11 \\
\hline$\varnothing 45$ & 58,82 & 3 & 133,71 & 83,86 & 2 & 147,40 & 48,14 & 4 & 145,90 & 48,89 & 4 & 148,18 \\
\hline$\varnothing 50$ & 67,71 & 3 & 153,93 & 96,17 & 2 & 169,04 & 55,75 & 4 & 168,97 & 56,67 & 3 & 128,84 \\
\hline
\end{tabular}

\section{KESIMPULAN}

Dari hasil analisis daya dukung pondasi dapat disimpulkan :

1. Berdasarkan Tingkat konsistensi tanah dari sondir (Terzaghi dan Peck, 1948), hasil penyelidikan tanah di lokasi proyek dan analisis pengujian sondir, dapat diketahui bahwa perlawanan penetrasi konus untuk kisaran kedalaman $1-5 \mathrm{~m}$ termasuk kategori Tanah Sedang/Kaku.

2. Berdasarkan analisis daya dukung pondasi dalam menggunakan metode Trofimankove (1974), metode Meyerhoff (1956), metode Begemann (1965), metode Cara Umum, pada kisaran kedalaman $4 \mathrm{~m}$ menunjukkan nilai yang berbeda pada masing-masing metode.

3. Penggunaan angka keamanan yang berbeda akan menghasilkan nilai daya dukung yang berbeda pula. Nilai daya dukung tiang tunggal yang rendah akan menghasilkan jumlah tiang lebih banyak dibandingkan nilai daya dukung tiang tunggal yang tinggi.

4. Jumlah tiang pancang sangat mempengaruhi nilai daya dukung tiang kelompok, semakin banyak tiang pancang yang digunakan, maka nilai daya dukung tiang kelompok semakin besar dan semakin aman untuk memikul beban bangunan, akan tetapi kurang ekonomis dari pertimbangan biaya.

\section{UCAPAN TERIMA KASIH}

Terima kasih kepada pihak-pihak yang telah membantu dalam penyelesaian penelitian ini dan terkhusus untuk Universitas Kadiri ynng telah mendukung penelitian ini baik secara moril ataupun materiil hingga penelitian ini dapat terselesaikan sesuai dengan yang diharapkan.

\section{DAFTAR PUSTAKA}

UU Nomer 28 Tahun 2002 Pasal 5 Ayat 1, Bangunan Gedung.

Thornburn,Thomas H.,1996,Teknik Fondasi edisi kedua,Gajah Mada University Press, Yogyakarta.

Bowless, J.E., 1988, Analisis dan Desain Pondasi Edisi Keempat Jilid 2 , Erlangga, Jakarta.

A., Hanggoro Tri Cahyo, 2006, Hand Out Rekayasa Pondasi 2, Pondasi Tiang Pancang, Jurusan Teknik Sipil -FT, Universitas Negeri Semarang.

Direktorat Jenderal Bina Marga. 1976. Manual Pemeriksaan Jalan. Departemen Pekerjaan Umum dan Tenaga Listrik : Jakarta.

Surendro, Dr. Bambang. 2015. Rekayasa Fondasi : Teori dan Penyelesaian Soal. Yogyakarta : Graha Ilmu.

Sunaryanto, Wahyu. 2012. Strauss Pile. (Online).

(http://belajarsipil.blogspot.co.id/2012/ 06/pondasi-strauss-pancang.html, diakses 13 Maret 2018). 
Tambunan, Jhonson, 2012, Studi Analisis Daya Dukung Pondasi Tiang Pancang, Jurnal Rancang Sipil, Vol. 1, No. $1: 21$ -30 .

Fahrani, Ferra dan Apriyanti, Yayuk, 2015, Analisis Daya Dukung Tanah dan Penurunan Pondasi Pada Daerah Pesisir Pantai Utara Kabupaten Bangka, Jurnal Fropil, Vol. 3, No. 2 : $89-95$.

Arifin, Zainul, 2007, Komparasi Daya Dukung Aksial Tiang Tunggal Dihitung dengan Beberapa Metode Analisis, Tesis, Program Pasca Sarjana, Universitas Diponegoro Semarang. 
Halaman ini sengaja dikosongkan 